\title{
Sodium-Glucose Co-Transporter 2 (SGLT2) Inhibitors: Are They All the Same? A Narrative Review of Cardiovascular Outcome Trials
}

\author{
David M. Williams (D) - Asif Nawaz · Marc Evans
}

Received: September 24, 2020 / Accepted: October 15, 2020 / Published online: November 13, 2020

(c) The Author(s) 2020

\begin{abstract}
Clinically important improvements in cardiovascular risk factors and adverse cardiovascular, heart failure and renal outcomes have been observed in numerous cardiovascular outcome trials (CVOTs) investigating the use of sodiumglucose co-transporter 2 (SGLT2) inhibitors over the last 5 years. However, differences in study outcomes between the various SGLT2 inhibitor CVOTs are often challenging to interpret because of differences in the study design, participant characteristics and primary outcomes of the various trials. In clinical practice, this frequently challenges the clinician when choosing between the different SGLT2 inhibitors for a patient with type 2 diabetes and various cardiovascular or renal comorbidities. Discussion around the choice of SGLT2 inhi-
\end{abstract}

D. M. Williams $(\bowtie) \cdot$ A. Nawaz $\cdot$ M. Evans Department of Diabetes and Endocrinology, University Hospital Llandough, Cardiff, UK e-mail: david.williams@doctors.org.uk bitor has been again revived by the recent publication of results from the VERTIS-CV, EMPEROR-reduced and DAPA-CKD trials investigating cardiovascular, heart failure and renal outcomes associated with various SGLT2 inhibitors.

This narrative review gives an overview of the mechanism of action and differences in the underlying pharmacology of the various SGLT2 inhibitors and discusses the key cardiovascular, heart failure and renal outcomes from completed CVOTs for SGLT2 inhibitors. Discussion highlights important differences in the study design and participant characteristics which limit the comparison of trials and medications within this drug class.

Keywords: Cardiovascular outcome trials; Chronic kidney disease; Heart failure; SGLT2 inhibitors; Type 2 diabetes 


\section{Key Summary Points}

Sodium-glucose co-transporter 2 (SGLT2) inhibitors broadly show a positive cardiovascular and renal impact in people with or without type 2 diabetes.

However, there are some inconsistencies with respect to 3-point major adverse cardiac event (3-P MACE) between different studies and drugs within this class.

Explanations including differences in study design, participant characteristics and pharmacology of the drugs in this class are discussed in this review.

Recently completed trials including the VERTIS-CV, EMPEROR-reduced and DAPA-CKD trials may shed light on reasons for the differences between completed cardiovascular outcome trials.

\section{DIGITAL FEATURES}

This article is published with digital features, including a summary slide, to facilitate understanding of the article. To view digital features for this article go to https://doi.org/10.6084/ m9.figshare.13089386.

\section{BACKGROUND}

Diabetes mellitus is associated with multi-system disease including microvascular complications (retinal disease, renal disease, neuropathy), macrovascular complications (ischaemic heart disease, peripheral vascular disease) and cardiac failure in addition to glycaemic complications such as hypoglycaemia and diabetic ketoacidosis (DKA). The burden of these complications in people with diabetes is substantial, resulting in significant morbidity and mortality frequently resulting in poor quality of life $[1,2]$. Moreover, the financial burden associated with treating diabetes-related complications is huge and is even greater than the direct costs of treating the disease [3]. Therefore, there is major interest in pharmacotherapies which improve complication rates to improve patient outcomes and ease the financial pressures associated with the increasing prevalence of diabetes.

Since the controversy surrounding the deleterious cardiovascular effects of rosiglitazone were observed in people with type 2 diabetes (T2D) [4], there has been growing regulatory interest in the non-glycaemic effects associated with diabetes medication use in people with T2D $[5,6]$. The importance of understanding the impact of drug therapies on cardiovascular outcomes is underlined by the burden of cardiovascular disease in T2D. A third of people with T2D have underlying cardiovascular disease and over $50 \%$ of people with T2D will die from a cardiovascular cause [7]. As such, specific cardiovascular outcomes are required to be reported for drug therapies used to treat T2D, including cardiovascular death, non-fatal myocardial infarction (MI) and non-fatal stroke [5], reported as a combined major adverse cardiovascular event (MACE) measure in cardiovascular outcome trials (CVOTs). Subsequently, several CVOTs have been undertaken to determine this effect with the newer drug classes used for T2D.

The use of sodium-glucose co-transporter 2 (SGLT2) inhibitors is now commonplace in the treatment of people with T2D since the licensing of dapagliflozin in 2012, and subsequent approval of other SGLT2 inhibitors such as canagliflozin, empagliflozin and ertugliflozin. Indeed, there is a growing body of evidence to suggest that SGLT2 inhibitors improve cardiovascular $[8,9]$ and renal [10] outcomes amongst other measures in people with T2D. Meta-analyses demonstrate a significant beneficial class effect associated with SGLT2 inhibitors, noting an $11 \%$ reduction in MACE and 23\% reduced risk of cardiovascular death or hospitalisation for heart failure (HHF) [9]. Nevertheless, there is some variability in the findings from individual CVOTs. For example, the VERTIS-CV study recently reported non-inferior MACE outcomes with ertugliflozin use compared with placebo 
[11], which is disappointing when compared with the superior MACE outcomes versus placebo previously associated with other SGLT2 inhibitors $[12,13]$. These results may reflect true differences between the various SGLT2 inhibitors or reflect disparities in study design and/or study participants which confound results and limit comparability. To address this, the US Food and Drug Administration (FDA) recently suggested minimum numbers of important study participant variables including age and proportion of people with underlying cardiovascular and/or renal disease to minimise confusion when comparing CVOTs and improve trial validity to real-world populations [14]. However, as more CVOTs report results it is increasingly difficult and confusing for clinicians to choose between SGLT2 inhibitors for their patients.

In this review, we compare SGLT2 inhibitors with completed CVOT results, illustrating similarities and differences in trial design, and key glycaemic, body weight, cardiovascular, renal and adverse event outcomes to support clinicians when choosing between these drugs.

This article is based on previously conducted studies and does not contain any studies with human participants or animals performed by any of the authors.

\section{MECHANISMS OF CARDIOVASCULAR AND RENAL BENEFIT WITH SGLT2 INHIBITION}

The inhibition of the SGLT2 protein in the proximal convoluted tubule of the nephron results in reduced renal sodium and glucose reuptake, the latter resulting in an enhanced daily urinary loss of up to $100 \mathrm{~g}$ of glucose $(200-300 \mathrm{kcal})$ [15]. This promotes natriuresis and glucose-mediated osmotic diuresis to improve several metabolic measures including glycaemic control, blood pressure, body weight, lipid profiles and stabilises renal function amongst others [9]. Nevertheless, the cardiovascular benefits associated with SGLT2 inhibitors are in excess of the predicted benefits associated with improvements in these cardiovascular risk factors [16]. As a result, several authors have suggested other mechanisms by which these drugs may indirectly and directly improve cardiovascular and renal outcomes.

Firstly, SGLT2 inhibitors indirectly improve cardiac function by enhancing diuresis and natriuresis to reduce plasma and interstitial fluid volumes thereby reducing cardiac preload [17]. Interestingly, the reduction in plasma volume is not associated with increased sympathetic nervous activity which may adversely affect cardiac outcomes [18]. Furthermore, as SGLT2 inhibition results in an increased delivery of sodium to the macula densa, tubuloglomerular feedback results in renal afferent arteriolar vasoconstriction to reduce the hyperfiltration which characterises the early stages of diabetic kidney disease and stabilises renal function over time. Interestingly, thiazide and loop diuretics which are frequently used to symptomatically treat people with heart failure do not result in tubuloglomerular feedback as these drugs block sodium entry to the macula densa $[19,20]$. Therefore, the use of SGLT2 inhibitors may be associated with more stable renal function associated with diuresis than that observed with the current use of thiazide or loop diuretics in the treatment of people with heart failure.

Further indirect mechanisms of SGLT2 inhibitor-mediated cardiovascular benefit include improved myocardial energy efficiency by shifting to ketone metabolism, a more energy efficient substrate than glucose or fatty acids. However, this effect is quite modest and some question the significance of this impact on cardiovascular outcomes [21]. Moreover, as SGLT2 inhibitors promote glycosuria these drugs induce a state of 'fasting mimicry' which activates the enzymes sirtuin 1 (SIRT1) and adenosine monophosphate-activated protein kinase (AMPK). As these enzymes have important anti-inflammatory effects within the heart, they may improve cardiac function [22].

Other putative direct mechanisms of cardiovascular benefit associated with these drugs include improved endothelial function [23], though this is often argued to be an indirect consequence of improved metabolic parameters generally associated with diabetes treatment. Further direct mechanisms suggested for the 

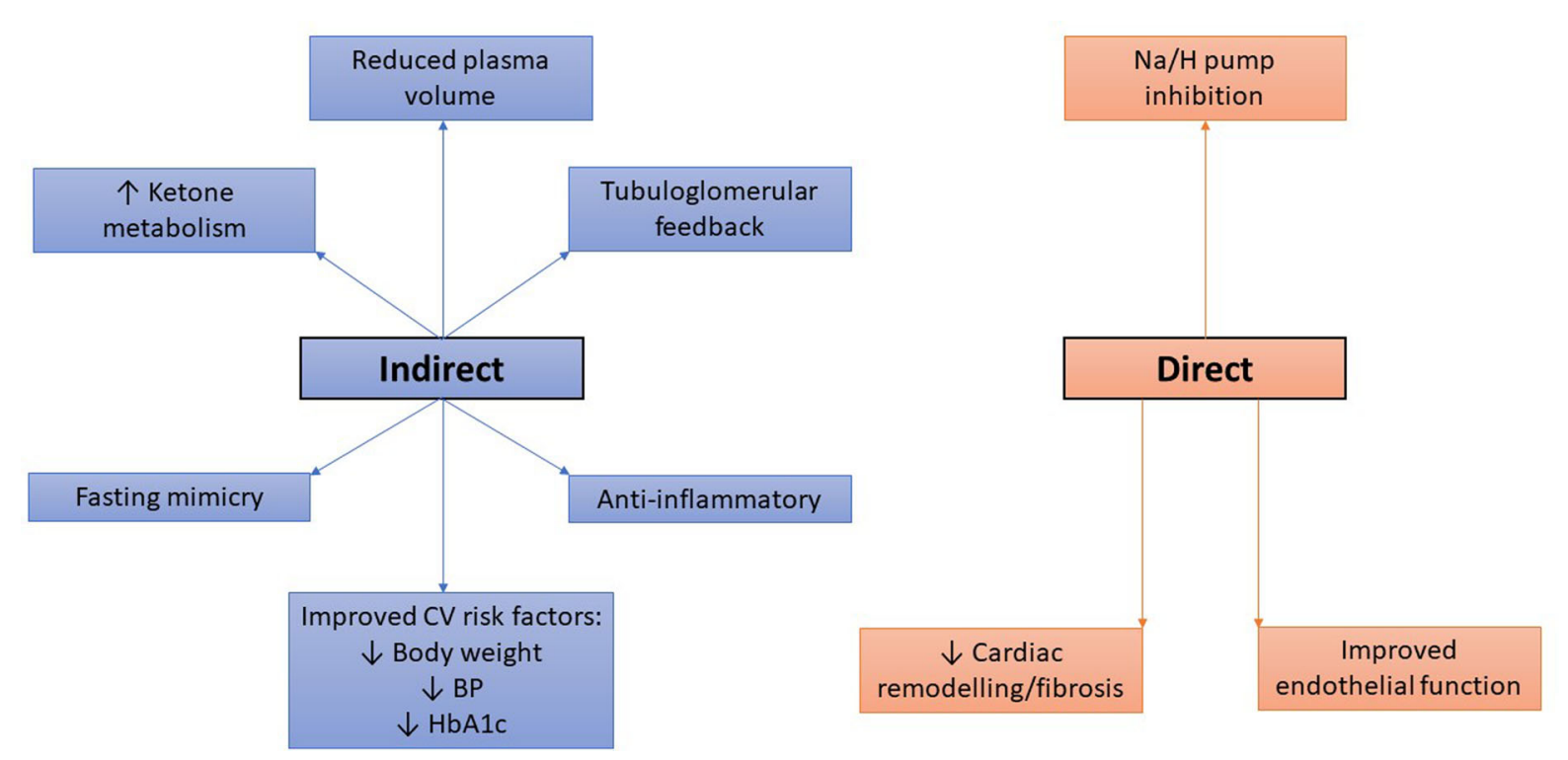

Fig. 1 Schematic summarising the potential direct and indirect mechanisms of cardiovascular benefits associated with SGLT2 inhibitor use. BP blood pressure, CV

cardiovascular, HbAlc glycated haemoglobin, $\mathrm{Na} / \mathrm{H}$ sodium/hydrogen [17-25]

benefits seen with SGLT2 inhibitors include direct myocardial $\mathrm{Na} / \mathrm{H}$ pump inhibition which improves sensitivity to endogenous natriuretic peptides, and reduces cardiac hypertrophy, fibrosis and remodelling [24]. Finally, SGLT2 inhibitors have also been shown to have antifibrotic effects to reduce cardiac remodelling and fibrosis [25]. Nevertheless, many of these mechanisms have only been observed in animal models and are yet to be corroborated in human studies. Figure 1 summarises the proposed direct and indirect mechanisms of cardiovascular benefit associated with SGLT2 inhibitors.

\section{SGLT2 INHIBITORS: DO THEY ALL WORK THE SAME WAY?}

As discussed previously, differences in trial outcomes may reflect differences in the mechanism and pharmacology of the various SGLT2 inhibitors, differences in trial design or study populations, or all of these factors. Differences in the pharmacology of these drugs including the dose, absorption, distribution, metabolism and excretion of these drugs as well as their relative affinity for the SGLT2 protein versus the

sodium-glucose co-transporter 1 (SGLT1) protein are important. The SGLT1 protein is expressed in the intestine and the late proximal convoluted tubule of the kidney, and functions to reabsorb glucose from the gut and the renal tubular glucose which escapes the more proximal SGLT2 protein. When SGLT2 is either overwhelmed or inhibited, there is upregulation of SGLT1 to limit glycosuria giving SGLT1 or dual SGLT1/SGLT2 inhibitors therapeutic potential in $\mathrm{T} 2 \mathrm{D}$, though evidence to support their use is limited [26]. Therefore, drugs which have varying affinity to inhibit SGLT2 and SGLT1 may have differing efficacy with respect to glycaemic control and other metabolic measures. For example, canagliflozin has the least SGLT2 selectivity of the currently licensed SGLT2 inhibitors and has been shown to delay the intestinal absorption of glucose [27].

As shown in Table 1 , there are several important differences in the pharmacology of these drugs [28-33]. Whilst the half-life, metabolism and elimination of these drugs are similar there is variable oral bioavailability of these drugs with the lowest observed in canagliflozin $(65 \%)$ and highest in ertugliflozin (100\%). The volume of distribution and plasma protein 
Table 1 Comparison of key pharmacological differences between SGLT2 inhibitors

\begin{tabular}{|c|c|c|c|c|c|c|}
\hline Drug (dose) & $\begin{array}{l}\text { Half-life } \\
\text { (hours) }\end{array}$ & $\begin{array}{l}\text { Oral } \\
\text { bioavailability } \\
(\%)\end{array}$ & $\begin{array}{l}\text { Volume of } \\
\text { distribution }(L)\end{array}$ & $\begin{array}{l}\text { Plasma protein } \\
\text { binding (\%) }\end{array}$ & $\begin{array}{l}\text { Metabolism and } \\
\text { elimination }\end{array}$ & $\begin{array}{l}\text { SGLT2 } \\
\text { selectivity (vs } \\
\text { SGLT1) }\end{array}$ \\
\hline $\begin{array}{l}\text { Canagliflozin } \\
(100-300 \mathrm{mg} \\
\text { OD) }\end{array}$ & $10.6-13.1$ & 65 & 83.5 & 98 & $\begin{array}{l}\text { Hepatic } \\
\quad \text { conjugated } \\
\text { Renal excretion }\end{array}$ & $\sim 250$ fold \\
\hline $\begin{array}{l}\text { Dapagliflozin } \\
(5-10 \mathrm{mg} \\
\text { OD) }\end{array}$ & 12.9 & 78 & 118 & 91 & $\begin{array}{l}\text { Hepatic } \\
\text { conjugated } \\
\text { Renal excretion }\end{array}$ & $\sim 1200$ fold \\
\hline $\begin{array}{l}\text { Empagliflozin } \\
(10-25 \mathrm{mg} \\
\text { OD) }\end{array}$ & 12.4 & 60 & 73.8 & 86.2 & $\begin{array}{l}\text { Hepatic } \\
\text { conjugated } \\
\text { Renal excretion }\end{array}$ & $\sim 2500$ fold \\
\hline $\begin{array}{l}\text { Ertugliflozin } \\
(5-15 \mathrm{mg} \\
\text { OD) }\end{array}$ & 16.6 & 100 & 85.5 & 93.6 & $\begin{array}{l}\text { Hepatic } \\
\text { conjugated } \\
\text { Renal excretion }\end{array}$ & $\sim 2000$ fold \\
\hline
\end{tabular}

Table 1 summarises the key pharmacological differences between clinically available SGLT2 inhibitors with reported CVOT data [28-33]

$S G L T$ sodium-glucose co-transporter, $O D$ once daily

binding also vary by drug. As previously discussed, canagliflozin has the least selectivity for the SGLT2 protein versus the SGLT1 protein $(\sim 250$ fold $)$ whilst empagliflozin has the highest ( $\sim 2500$ fold). Thus, whilst these drugs work by a similar mechanism such pharmacological differences may account for some of the variation in clinical outcomes observed with these drugs.

\section{CARDIOVASCULAR OUTCOME TRIALS AND SGLT2 INHIBITORS}

\section{Study Design and Baseline Characteristics}

To date, trials evaluating cardiovascular and renal measures have been reported for several SGLT2 inhibitors including dapagliflozin [34-39], canagliflozin [13, 40, 41], empagliflozin $[12,42,43]$ and ertugliflozin $[11,44]$. The largest trial so far is the DECLARE-TIMI trial which evaluated dapagliflozin in 17,160 participants over a median 4.2 years [34]. There is some variability in the trial design of studies reporting cardiovascular and renal outcomes with the number of participants varying between 3730 and 17,160 people, and trial duration between 16 months and 4.2 years. The numbers of participants and trial duration required often reflect the anticipated event rate to draw statistical conclusions, and therefore the variability in these features may reflect the likelihood of each trial population attaining a cardiovascular and/or renal endpoint. Additionally, there are differences in the proportion of participants in these trials with underlying co-morbidities such as heart failure or renal disease. Moreover, the reporting of whether baseline heart failure status is associated with a reduced ejection fraction (HFrEF) or preserved ejection fraction (HFpEF) is inconsistent. Essentially, each of the studies has a population with different co-morbidities and risk factors which confer variable risk and different rates of cardiovascular or renal events during a trial. Similarities and disparities in trial design and participant characteristics between CVOTs are shown in Table 2. 
Table 2 Key differences in study design and participant characteristics in completed CVOTs of SGLT2 inhibitors

\begin{tabular}{|c|c|c|c|c|c|c|c|}
\hline \multirow{2}{*}{$\begin{array}{l}\text { Trial } \\
{[\text { Drug }]}\end{array}$} & \multirow{2}{*}{$\begin{array}{l}\text { Participant } \\
\text { number } \\
\text { Median } \\
\text { follow-up }\end{array}$} & \multicolumn{5}{|c|}{ Participant characteristics } & \multirow[t]{2}{*}{ Primary outcomes } \\
\hline & & $\begin{array}{l}\text { Mean } \\
\text { HbAlc } \\
{[\mathrm{mmol} / \mathrm{mol}]} \\
\quad(\%)\end{array}$ & $\begin{array}{l}\text { Mean } \\
\text { BMI } \\
(\mathrm{kg} / \\
\left.\mathrm{m}^{2}\right)\end{array}$ & Heart failure & $\begin{array}{l}\text { Mean } \\
\text { systolic } \\
\text { BP } \\
(\mathrm{mmHg})\end{array}$ & $\begin{array}{l}\text { Mean } \\
\text { eGFR } \\
(\mathrm{mL} / \mathrm{min} / \\
\left.1.73 \mathrm{~m}^{2}\right)\end{array}$ & \\
\hline $\begin{array}{l}\text { DECLARE- } \\
\text { TIMI } \\
\text { [Dapagliflozin] }\end{array}$ & $\begin{array}{l}n=17,160 \\
\text { Follow-up } \\
4.2 \text { years }\end{array}$ & $67(8.3)$ & 32.1 & $\begin{array}{l}\text { HFrEF: } 671 \\
\quad(3.9 \%) \\
\text { HFpEF: } 1316 \\
(7.7 \%)\end{array}$ & 135.0 & 85.2 & $\begin{array}{l}\text { 3-P MACE } \\
\text { Composite of CV death or } \\
\text { HHF }\end{array}$ \\
\hline $\begin{array}{l}\text { DAPA-HF } \\
\text { [Dapagliflozin] }\end{array}$ & $\begin{array}{l}n=4744 \\
\text { Follow-up } \\
18.2 \text { months }\end{array}$ & $\begin{array}{l}\text { T2D-41.8\% } \\
\text { Non-T2D- } \\
58.2 \%\end{array}$ & 28.2 & $\begin{array}{l}\text { HFrEF: } 4744 \\
\quad(100 \%) \\
\text { HFpEF: } 0(0 \%)\end{array}$ & 121.8 & 65.8 & $\begin{array}{l}\text { Composite of worsening heart } \\
\text { failure or } \mathrm{CV} \text { death }\end{array}$ \\
\hline $\begin{array}{l}\text { DAPA-CKD } \\
\text { [Dapagliflozin] }\end{array}$ & $\begin{array}{c}n=4304 \\
\text { Follow-up } \\
2.4 \text { years }\end{array}$ & $\begin{array}{l}\mathrm{T} 2 \mathrm{D}-67.5 \% \\
\text { Non-T2D- } \\
32.5 \%\end{array}$ & 29.5 & $\begin{array}{l}\text { HF } \\
\qquad \text { (unspecified): } \\
\qquad 468(10.9 \%)\end{array}$ & 137.1 & 43.1 & $\begin{array}{l}\text { Composite of } \\
\text { sustained } \geq 50 \% \text { eGFR } \\
\text { decline, ESRD, renal death } \\
\text { or CV death }\end{array}$ \\
\hline $\begin{array}{l}\text { CANVAS } \\
\text { [Canagliflozin] }\end{array}$ & $\begin{array}{l}n=10,142 \\
\text { Follow-up } \\
188.2 \text { weeks }\end{array}$ & $66(8.2)$ & 32.0 & $\begin{array}{l}\text { HF } \\
\text { (unspecified): } \\
1461(14.4 \%)\end{array}$ & 136.6 & 76.5 & 3-P MACE \\
\hline $\begin{array}{l}\text { CREDENCE } \\
{[\text { Canagliflozin }]}\end{array}$ & $\begin{array}{c}n=4401 \\
\text { Follow-up } \\
2.6 \text { years }\end{array}$ & $67(8.3)$ & 31.3 & $\begin{array}{l}\text { HF } \\
\qquad \text { (unspecified): } \\
\quad 652(14.8 \%)\end{array}$ & 140.0 & 56.2 & $\begin{array}{l}\text { A composite of ESRD, } \\
\text { doubling serum creatinine, } \\
\text { or death from renal or CV } \\
\text { disease }\end{array}$ \\
\hline $\begin{array}{l}\text { EMPA-REG } \\
\text { [Empagliflozin] }\end{array}$ & $\begin{array}{c}n=7020 \\
\text { Follow-up } \\
3.1 \text { years }\end{array}$ & $65(8.1)$ & 30.6 & $\begin{array}{l}\text { HF } \\
\qquad \text { (unspecified): } \\
706(10.1 \%)\end{array}$ & 135.6 & 74.0 & 3-P MACE \\
\hline $\begin{array}{l}\text { EMPORER- } \\
\text { reduced } \\
\text { [Empagliflozin] }\end{array}$ & $\begin{array}{l}n=3730 \\
\text { Follow-up } \\
16 \text { months }\end{array}$ & $\begin{array}{l}\mathrm{T} 2 \mathrm{D}-49.8 \% \\
\text { Non-T2D- } \\
50.2 \%\end{array}$ & 27.9 & $\begin{array}{l}\text { HFrEF: } 3730 \\
\qquad(100 \%) \\
\text { HFpEF: } 0(0 \%)\end{array}$ & 122.0 & 62.0 & $\begin{array}{l}\text { A composite of } \mathrm{CV} \text { death or } \\
\text { HHF }\end{array}$ \\
\hline $\begin{array}{l}\text { VERTIS-CV } \\
{[\text { Ertugliflozin }]}\end{array}$ & $\begin{array}{c}n=8238 \\
\text { Follow-up } \\
3.5 \text { years }\end{array}$ & $66(8.2)$ & 32.0 & $\begin{array}{l}\text { HF } \\
\quad \text { (unspecified): } \\
\text { Ertugliflozin } \\
23.4 \% \\
\text { Placebo } 24.5 \%\end{array}$ & 133.3 & 76.0 & 3-P MACE \\
\hline
\end{tabular}

Table 2 summarises the key differences and similarities in trial design and participant characteristics for each of the major trials reporting cardiovascular and/or renal outcome measures [11-13, 34, 35, 38, 40, 41, 43, 44]. 3-point MACE is a composite of cardiovascular death, non-fatal myocardial infarction and non-fatal stroke

3-P MACE 3-point major cardiovascular adverse events, $B M I$ body mass index, $B P$ blood pressure, $C V$ cardiovascular, $e G F R$ estimated glomerular filtration rate, $E S R D$ end-stage renal disease, $H b A 1 c$ glycated haemoglobin, $H F$ heart failure, $H F r E F$ heart failure with reduced ejection fraction, $H F p E F$ heart failure with preserved ejection fraction, $H H F$ hospitalisation for heart failure, T2D type 2 diabetes 


\section{Changes in Cardiovascular Risk Factors}

Across each of the cardiovascular and renal outcome studies investigating SGLT2 inhibitor use, there are consistent improvements in glycaemic control, systolic blood pressure and body weight associated with their use. These results are presented in Table 3 . However, there is some variation in the degree of change between studies. For example, the EMPA-REG trial found that empagliflozin use resulted in a mean improvement in glycated haemoglobin (HbA1c) of just $2 \mathrm{mmol} / \mathrm{mol}$ (0.24\%) over 206 weeks, compared with an improvement of $6 \mathrm{mmol} / \mathrm{mol}(0.58 \%)$ in the CANVAS program investigating canagliflozin over 188 weeks. Baseline HbA1c and the other key baseline characteristics in these studies were similar, suggesting that pharmacological differences may be clinically significant between these drugs.

Changes in body weight in the main CVOTs were similar with a mean weight loss of $1.6-2.2 \mathrm{~kg}$. Understandably, trials investigating heart failure outcomes (DAPA-HF and EMPEROR-reduced) demonstrated lesser weight loss of about $0.8 \mathrm{~kg}$ probably because of their lower mean BMI at baseline [35, 43]. However, the CREDENCE trial which investigated renal outcomes with canagliflozin noted poorer weight loss and $\mathrm{HbA1c}$ reductions compared to other CVOTs including the CANVAS study which also investigated canagliflozin despite similar baseline BMI and HbA1c [13, 40]. Differences in weight loss may therefore reflect the poorer baseline renal function observed in the CREDENCE cohort, highlighting how differences in baseline participant characteristics can impact trial outcome results. Unfortunately changes in these cardiovascular risk factors have not yet been published for the DAPA-CKD trial which recruited a similar cohort as CREDENCE, and we await these results with interest.

\section{Renal Outcomes}

We previously reviewed renal outcomes from completed CVOTs [10]. Participants in each of the main CVOTs were observed to have a baseline eGFR $>60 \mathrm{~mL} / \mathrm{min} / 1.73 \mathrm{~m}^{2}$, with the DECLARE-TIMI trial participants demonstrating the highest mean eGFR of $85.2 \mathrm{~mL} / \mathrm{min} / 1.73 \mathrm{~m}^{2}$ and the EMPA-REG trial demonstrating the lowest mean eGFR at $74.0 \mathrm{~mL} / \mathrm{min} / 1.73 \mathrm{~m}^{2}$ $[12,34]$. Unsurprisingly, the mean baseline eGFR of the dedicated renal outcome trials was much lower at 56.2 and $43.1 \mathrm{~mL} / \mathrm{min} / 1.73 \mathrm{~m}^{2}$ in the CREDENCE and DAPA-CKD trials, respectively $[38,40]$.

The proportion of participants attaining the renal endpoint was consistently lower in all SGLT2 inhibitor trials compared with placebo, as shown in Table 3. However, it is worth noting that the renal endpoint varied between studies, usually a composite of sustained changes in eGFR or serum creatinine, occurrence of endstage renal disease (ESRD) and renal or cardiovascular death. Similarly, trials which reported changes in urinary albumin excretion consistently observed significant improvements with SGLT2 inhibitors. Trials variably reported changes in the eGFR, though significant deterioration in eGFR and decline in mean eGFR over the study period were significantly less likely with SGLT2 inhibitor use. Importantly, both CREDENCE and DAPA-CKD which investigated renal outcomes in people with poorer baseline renal function demonstrated clinically important improvements in renal outcomes $[39,40]$. Interestingly, in DAPA-CKD the impact on renal outcomes was observed in people both with and without T2D [39], though this was not assessed in the CREDENCE trial as people without T2D were not included.

\section{Inconsistencies and Similarities in Cardiovascular Outcomes: 3-P MACE, Mortality and HHF}

Whilst these trials each explore similar cardiovascular outcomes associated with SGLT2 inhibitors with a similar trial design, there appears to be inconsistent cardiovascular benefit associated with these drugs. All SGLT2 inhibitor CVOTs so far have demonstrated safety (noninferiority) for 3-point MACE versus placebo. However, cardiovascular superiority for 3-point MACE has been demonstrated for empagliflozin 
Table 3 Differences in study outcomes in completed CVOTs of SGLT2 inhibitors use

\begin{tabular}{|c|c|c|c|c|c|c|}
\hline $\begin{array}{l}\text { Trial } \\
{[\text { Drug }]}\end{array}$ & HbAlc & $\begin{array}{l}\text { Body } \\
\text { weight }\end{array}$ & Systolic BP & $\begin{array}{l}\text { Composite renal } \\
\text { outcome measure }\end{array}$ & Changes in eGFR & $\begin{array}{l}\text { Progression of } \\
\text { albuminuria }\end{array}$ \\
\hline $\begin{array}{l}\text { DECLARE- } \\
\text { TIMI }\end{array}$ & $\begin{array}{c}-4 \mathrm{mmol} / \mathrm{mol} \\
(0.42 \%)\end{array}$ & $-1.80 \mathrm{~kg}$ & $-2.7 \mathrm{mmHg}$ & $\begin{array}{l}\text { HR } 0.53 \\
\text { [CI } 0.43-0.66]\end{array}$ & $\begin{array}{l}\text { Sustained eGFR } \\
\text { decline }\end{array}$ & $\begin{array}{l}\text { HR } 0.84 \\
\text { [CI } 0.79-0.89]\end{array}$ \\
\hline [Dapagliflozin] & & & & & $\begin{array}{l}\text { HR } 0.54 \\
\text { [CI } 0.43-0.67 \text { ] }\end{array}$ & \\
\hline $\begin{array}{l}\text { DAPA-HF } \\
\text { [Dapagliflozin] }\end{array}$ & $\begin{array}{c}-2 \mathrm{mmol} / \mathrm{mol} \\
(0.24 \%)\end{array}$ & $-0.87 \mathrm{~kg}$ & $-1.3 \mathrm{mmHg}$ & $\begin{array}{l}\text { HR } 0.71 \\
{[\text { CI } 0.44-1.16]}\end{array}$ & - & - \\
\hline $\begin{array}{l}\text { DAPA-CKD } \\
\text { [Dapagliflozin] }\end{array}$ & $* *$ & $* *$ & ** & $\begin{array}{l}\text { HR } 0.61 \\
{[\text { CI } 0.51-0.72]}\end{array}$ & $* *$ & ** \\
\hline $\begin{array}{l}\text { CANVAS } \\
{[\text { Canagliflozin }]}\end{array}$ & $\begin{array}{c}-6 \mathrm{mmol} / \mathrm{mol} \\
(0.58 \%)\end{array}$ & $-1.60 \mathrm{~kg}$ & $-3.9 \mathrm{mmHg}$ & $\begin{array}{l}\text { HR } 0.53 \\
{[\text { CI } 0.33-0.84]}\end{array}$ & $\begin{array}{l}\text { Annual change in } \\
\text { eGFR versus } \\
\text { placebo } \\
+1.2 \mathrm{~mL} / \mathrm{min} / \\
1.73 \mathrm{~m}^{2}\end{array}$ & $\begin{array}{l}\text { HR } 0.80 \\
{\left[\begin{array}{ll}\text { CI } & 0.73-0.87\end{array}\right]}\end{array}$ \\
\hline $\begin{array}{l}\text { CREDENCE } \\
\text { [Canagliflozin] }\end{array}$ & $\begin{array}{c}-2 \mathrm{mmol} / \mathrm{mol} \\
(0.25 \%)\end{array}$ & $-0.80 \mathrm{~kg}$ & $-3.3 \mathrm{mmHg}$ & $\begin{array}{l}\text { HR } 0.66 \\
{[\text { CI } 0.53-0.81]}\end{array}$ & $\begin{array}{l}\text { Double serum } \\
\text { creatinine } \\
\text { HR } 0.60[\mathrm{CI} \\
0.48-0.76]\end{array}$ & $\begin{array}{c}\text { Mean UACR } \\
31 \% \text { lower } \\
\text { [CI 26-35\%] }\end{array}$ \\
\hline $\begin{array}{l}\text { EMPA-REG } \\
\text { [Empagliflozin] }\end{array}$ & $\begin{array}{c}-2 \mathrm{mmol} / \mathrm{mol} \\
(0.24 \%)\end{array}$ & $-2.0 \mathrm{~kg}$ & $-\sim 2.0 \mathrm{mmHg}$ & $\begin{array}{l}\text { HR } 0.61 \\
{[\text { CI } 0.53-0.70]}\end{array}$ & $\begin{array}{l}\text { Doubling serum } \\
\text { creatinine } \\
\text { HR } 0.56[\mathrm{CI} \\
0.39-0.79]\end{array}$ & $\begin{array}{l}\text { HR } 0.62 \\
{[\text { CI } 0.54-0.72]}\end{array}$ \\
\hline $\begin{array}{l}\text { EMPORER- } \\
\text { reduced } \\
\text { [Empagliflozin] }\end{array}$ & $\begin{array}{c}-1.5 \mathrm{mmol} / \mathrm{mol} \\
(0.16 \%)\end{array}$ & $-0.82 \mathrm{~kg}$ & $-0.7 \mathrm{mmHg}$ & $\begin{array}{l}\text { HR } 0.50 \\
{[0.32-0.77]}\end{array}$ & $\begin{array}{l}\text { Annual change in } \\
\text { eGFR versus } \\
\text { placebo } \\
+1.73 \mathrm{~mL} / \mathrm{min} / \\
1.73 \mathrm{~m}^{2}\end{array}$ & - \\
\hline $\begin{array}{l}\text { VERTIS-CV } \\
\text { [Ertugliflozin] }\end{array}$ & $\begin{array}{c}-5 \mathrm{mmol} / \mathrm{mol} \\
(0.50 \%)\end{array}$ & $-2.2 \mathrm{~kg}$ & $-2.9 \mathrm{mmHg}$ & $\begin{array}{l}\text { HR } 0.81 \\
{[\text { CI } 0.63-1.04]}\end{array}$ & $\begin{array}{l}\text { Annual change in } \\
\text { eGFR versus } \\
\text { placebo } \\
+3.03 \mathrm{~mL} / \mathrm{min} / \\
1.73 \mathrm{~m}^{2}\end{array}$ & - \\
\hline
\end{tabular}

Table 3 summarises the key cardiovascular risk factor and renal outcomes from completed CVOTs investigating SGLT2 inhibitors [11-13, 34-44]

$B P$ blood pressure, $C I$ confidence interval, $C V$ cardiovascular, eGFR estimated glomerular filtration rate, HbAIc glycated haemoglobin, $H H F$ heart failure hospitalisation, $H R$ hazard ratio, $M I$ myocardial infarction, $U A C R$ urinary albumin-to-creatinine ratio

${ }^{* *}$ Awaiting full publication of results 
(EMPA-REG) [12] and canagliflozin (CANVAS and CREDENCE) $[13,40]$, but not for dapagliflozin (DECLARE-TIMI) [34] or ertugliflozin (VERTIS-CV) [11]. Further confusion arises when we compare cardiovascular outcomes from the heart failure outcome trials published to date; DAPA-HF (dapagliflozin) and EMPEROR-reduced (empagliflozin). These trials only included participants with HFrEF. In contrast with the previous CVOTs for each of these drugs, dapagliflozin significantly reduced the risk of cardiovascular death versus placebo in DAPA-HF, whilst empagliflozin did not reduce cardiovascular death in EMPEROR-reduced $[35,43]$.

With respect to hospitalisation for heart failure (HHF) outcomes, all trials consistently showed superior outcomes versus placebo. Interestingly, the superior primary cardiovascular outcome of CV death or HHF was observed in participants with or without underlying T2D in the DAPA-HF and EMPEROR-reduced trials $[35,43]$. Indeed, superiority for the combined outcome of cardiovascular death or HHF in the DECLARE-TIMI trial was driven by the significant reduction in HHF [34]. Similarly, in renal outcome trials SGLT2 inhibitors appear to reduce HHF as shown in CREDENCE and DAPACKD. In DAPA-CKD the composite risk of HHF or cardiovascular death was $29 \%$ lower than placebo (HR 0.71, CI 0.55-0.92) [39], and we await the full publication of results. Across all the completed CVOTs there was no statistical difference compared with placebo for non-fatal MI or stroke. All-cause mortality was significantly lower in the EMPA-REG and DAPA-HF trials, though this was largely driven by the reduction in cardiovascular mortality already discussed.

Table 4 summarises the major cardiovascular and HHF outcomes observed in each of the completed cardiovascular, renal and heart failure outcome trials to date.

\section{Why Are There Inconsistent Results in CVOTS?}

Explaining the differences between trials is challenging. Participants in the main CVOTs had similar mean HbA1c, BMI and systolic blood pressure at baseline. Of course, populations in the heart failure outcome trials (DAPAHF and EMPEROR-reduced) were quite different as all participants were diagnosed with HFrEF and observed to have lower BMI, systolic blood pressure and mean eGFR, and included participants without T2D. However, there were no significant differences in cardiovascular outcomes in people with or without T2D in either of the heart failure outcome trials. Similarly, participants in the renal outcome trials (CREDENCE and DAPA-CKD) were observed to have lower mean BMI and eGFR than participants included in previous CVOTs investigating these drugs and demonstrated good cardiovascular and renal outcome results $[39,40]$.

A major difference in the study population in the VERTIS-CV trial was the higher proportion of participants with heart failure $(\sim 24 \%)$ compared with other major CVOTs ( 10-15\%). Additionally, over $80 \%$ of the participants with heart failure in VERTIS-CV had HFpEF and less than 20\% had HFrEF [11], which may have skewed the results as the effect of SGLT2 inhibitors in HFpEF is currently unknown. The ongoing EMPEROR-preserved and DELIVER trials will soon publish their results on the effect of empagliflozin and dapagliflozin in this difficult-to-treat population and may shed light on this discussion point $[45,46]$. Indeed, the proportion of HFpEF compared with HFrEF in other major CVOTs including DECLARE-TIMI is unknown and may have affected these results as we know SGLT2 inhibitors improved cardiovascular mortality in DAPA-HF, at least.

Differences in the population risk for cardiovascular events in different trials may also affect the statistical interpretation of cardiovascular outcomes. Whilst the EMPA-REG and VERTIS-CV trials included only participants with established atherosclerotic cardiovascular disease, CANVAS and DECLARE-TIMI included participants with either established atherosclerotic cardiovascular disease or multiple cardiovascular risk factors. This is reflected in the cardiovascular event rate between trials, as DECLARE-TIMI had the lowest cardiovascular event rate per 1000 patient years compared with 
Table 4 Differences in study outcomes in completed CVOTs of SGLT2 inhibitors use

\begin{tabular}{|c|c|c|c|c|c|c|}
\hline Trial [Drug] & 3-P MACE & CV death & $\begin{array}{l}\text { Non-fatal } \\
\text { MI }\end{array}$ & $\begin{array}{l}\text { Non-fatal } \\
\text { stroke }\end{array}$ & $\begin{array}{l}\text { All-cause } \\
\text { mortality }\end{array}$ & HHF \\
\hline DECLARE-TIMI & HR 0.93 & HR 0.98 & HR 0.89 & HR 1.01 & HR 0.93 & HR 0.73 \\
\hline [Dapagliflozin] & $\begin{array}{l}{[\mathrm{CI}} \\
\quad 0.84-1.03]^{\dagger}\end{array}$ & $\begin{array}{l}{[\mathrm{CI}} \\
\quad 0.82-1.17]\end{array}$ & $\begin{array}{l}{[\mathrm{CI}} \\
\quad 0.77-1.01]\end{array}$ & [CI $0.84-1.21]$ & [CI $0.82-1.04$ ] & $\begin{array}{l}{[\mathrm{CI}} \\
\quad 0.61-0.88]\end{array}$ \\
\hline DAPA-HF & - & HR 0.82 & - & - & HR 0.83 & HR 0.70 \\
\hline [Dapagliflozin] & & $\begin{array}{l}{[\mathrm{CI}} \\
\quad 0.69-0.98]\end{array}$ & & & [CI $0.71-0.97$ ] & $\begin{array}{l}{[\mathrm{CI}} \\
\quad 0.59-0.83]\end{array}$ \\
\hline $\begin{array}{l}\text { DAPA-CKD } \\
\text { [Dapagliflozin] }\end{array}$ & $* *$ & $* *$ & $* *$ & $* *$ & $\begin{array}{l}\text { HR } 0.69 \\
{\left[\begin{array}{ll}\text { CI } & 0.53-0.88\end{array}\right]}\end{array}$ & ** \\
\hline CANVAS & HR 0.86 & HR 0.87 & HR 0.85 & HR 0.90 & HR 0.87 & HR 0.67 \\
\hline [Canagliflozin] & $\begin{array}{l}{[\mathrm{CI}} \\
0.75-0.97]^{\dagger \dagger}\end{array}$ & {$[0.72-1.06]$} & {$[0.69-1.05]$} & [CI $0.71-1.15$ ] & {$[0.74-1.01]$} & $\begin{array}{l}{[\mathrm{CI}} \\
\quad 0.52-0.87]\end{array}$ \\
\hline CREDENCE & HR 0.80 & HR 0.78 & - & - & HR 0.83 & HR 0.61 \\
\hline [Canagliflozin] & $\begin{array}{l}{[\mathrm{CI}} \\
0.67-0.95]^{\dagger \dagger}\end{array}$ & $\begin{array}{l}{[\mathrm{CI}} \\
\quad 0.61-1.00]\end{array}$ & & & [CI $0.68-1.02]$ & $\begin{array}{l}{[\mathrm{CI}} \\
\quad 0.47-0.80]\end{array}$ \\
\hline EMPA-REG & HR 0.86 & HR 0.62 & HR 0.87 & HR 1.24 & HR 0.68 & HR 0.65 \\
\hline [Empagliflozin] & $\begin{array}{l}{[\mathrm{CI}} \\
0.74-0.99]^{\dagger \dagger}\end{array}$ & $\begin{array}{l}{[\mathrm{CI}} \\
\quad 0.49-0.77]\end{array}$ & [0.70-1.09] & [CI $0.92-1.67]$ & [CI $0.57-0.82$ ] & $\begin{array}{l}{[\mathrm{CI}} \\
\quad 0.50-0.85]\end{array}$ \\
\hline $\begin{array}{l}\text { EMPORER- } \\
\text { reduced }\end{array}$ & - & $\begin{array}{l}\text { HR } 0.92 \\
{[\mathrm{CI}}\end{array}$ & - & - & $\begin{array}{l}\text { HR } 0.92 \\
{[\text { CI } 0.77-1.10]}\end{array}$ & $\begin{array}{l}\mathrm{HR} 0.69 \\
{[\mathrm{CI}}\end{array}$ \\
\hline [Empagliflozin] & & $0.75-1.12]$ & & & & $0.59-0.81]$ \\
\hline VERTIS-CV & HR 0.97 & HR 0.92 & HR 1.00 & HR 1.00 & - & HR 0.70 \\
\hline [Ertugliflozin] & $\begin{array}{l}{[\mathrm{CI}} \\
\quad 0.85-1.11]^{\dagger}\end{array}$ & $\begin{array}{l}{[\mathrm{CI}} \\
\quad 0.77-1.11]\end{array}$ & $\begin{array}{l}{[\mathrm{CI}} \\
\quad 0.86-1.27]\end{array}$ & {$[0.76-1.32]$} & & $\begin{array}{l}{[\mathrm{CI}} \\
\quad 0.54-0.90]\end{array}$ \\
\hline
\end{tabular}

Table 4 summarises the key glycaemic, cardiovascular and other outcomes from completed CVOTs investigating the use of SGLT2 inhibitors [11-13, 34, 35, 39-41, 43]. 3-point MACE is a composite of cardiovascular death, non-fatal myocardial infarction and non-fatal stroke

3-P MACE 3-point major adverse cardiovascular event, $C I$ confidence interval, $C V$ cardiovascular, $H b A 1 c$ glycated haemoglobin, $H H F$ hospitalisation for heart failure, $H R$ hazard ratio, $M I$ myocardial infarction

$\dagger$ Denotes statistical significance for non-inferiority versus placebo

$\dagger \dagger$ Denotes statistical significance for superiority versus placebo

${ }^{* *}$ Awaiting full publication of results

CANVAS and EMPA-REG trials. This may cause a statistical artefact resulting in statistical insignificance between the dapagliflozin and placebo arms of the trial [47]. Unfortunately, at the time of writing a comparative event rate per 1000 patient years with the VERTIS-CV study was not available as we await the full publication of trial outcomes.

Pharmacological differences such as SGLT2 selectivity would not explain this difference in 3-point MACE because empagliflozin demonstrates greatest selectivity whilst canagliflozin 
demonstrates the least SGLT2 selectivity and trials including these SGLT2 inhibitors demonstrated superiority for 3-point MACE. Other differences in the pharmacological properties between drugs do not appear to be able to explain the differences in trial outcomes.

Despite trials including large study populations observed over years, differences in study outcomes simply due to chance cannot be refuted. This is especially supported by the conflicting mortality results between trials for the same drug, for example empagliflozin (EMPA-REG and EMPEROR-preserved) and dapagliflozin (DECLARE-TIMI and DAPA-HF) with respect to cardiovascular death outcomes. Nevertheless, differences in the proportion of participants with heart failure and specifically HFpEF in the VERTIS-CV trial and the low cardiovascular event rate in the DECLARE-TIMI trial may explain why these trials did not demonstrate superiority for 3-point MACE whilst the EMPA-REG and CANVAS trials did.

\section{ADVERSE EVENTS}

The rates of adverse events associated with SGLT2 inhibitors including rates of genitourinary infections, DKA, acute kidney injury and hypoglycaemia from completed CVOTs to date are shown in Table 5 .

\section{Acute Diabetes Complications}

The rates of DKA were significantly higher in the DECLARE-TIMI and CREDENCE trials and trended to increased rates in other studies except those investigating empagliflozin. This is difficult to explain, though may reflect the drug's differing pharmacological properties such as its greater SGLT2 selectivity, amongst others. A previous meta-analysis of randomised controlled trials investigating SGLT2 inhibitors observed significantly higher rates of DKA in those using SGLT2 inhibitors versus control, particularly in people aged over 60 years [48]. Differences in the mean age of participants between CVOTs does not explain the different risk of DKA as the mean age of participants across CVOTs is similar. The use of SGLT2 inhibitors did not increase the rate of hypoglycaemia in any major CVOT, and hypoglycaemia rates were significantly lower in the DECLARETIMI trial. The reasons for this difference are unclear, though like other SGLT2 inhibitor trials, the DAPA-HF and DAPA-CKD studies did not demonstrate significant changes in hypoglycaemia rates. We speculate that differences were either a result of chance or differences in other medication changes during the trial such as the co-prescription of sulfonylureas and/or insulin.

\section{Genitourinary Infections and Acute Kidney Injury}

Given the mechanism by which SGLT2 inhibitors improve hyperglycaemia, an increased incidence of genital and or urinary tract infections secondary to the increased glycosuria is possible. Consistently across each of the trials, the rate of genital tract infection was higher in those using SGLT2 inhibitors and the rate of urinary tract infections was only significantly higher in the VERTIS-CV study. Similar realworld findings have been identified in people with T2D using SGLT2 inhibitors compared with other classes of medication for diabetes [49]. There was a significantly lower rate of acute kidney injury (AKI) associated with SGLT2 inhibitor use in the DECLARE-TIMI and EMPAREG trials, and a trend to reduced AKI incidence in all other CVOTs to date. These findings are also supported by recent real-world analyses of people with T2D using this class of medication [50].

\section{Bone Fractures and Limb Amputation}

The frequency of either bone fractures or limb amputation was only statistically significantly higher in the CANVAS study, and not significantly different in any other CVOT. As canagliflozin has significantly lower selectivity for SGLT2 versus SGLT1, some authors have suggested this may explain the increased fracture risk [51]. However, there is no clear biological mechanism which would support this suggestion, as the SGLT1 protein has not been 


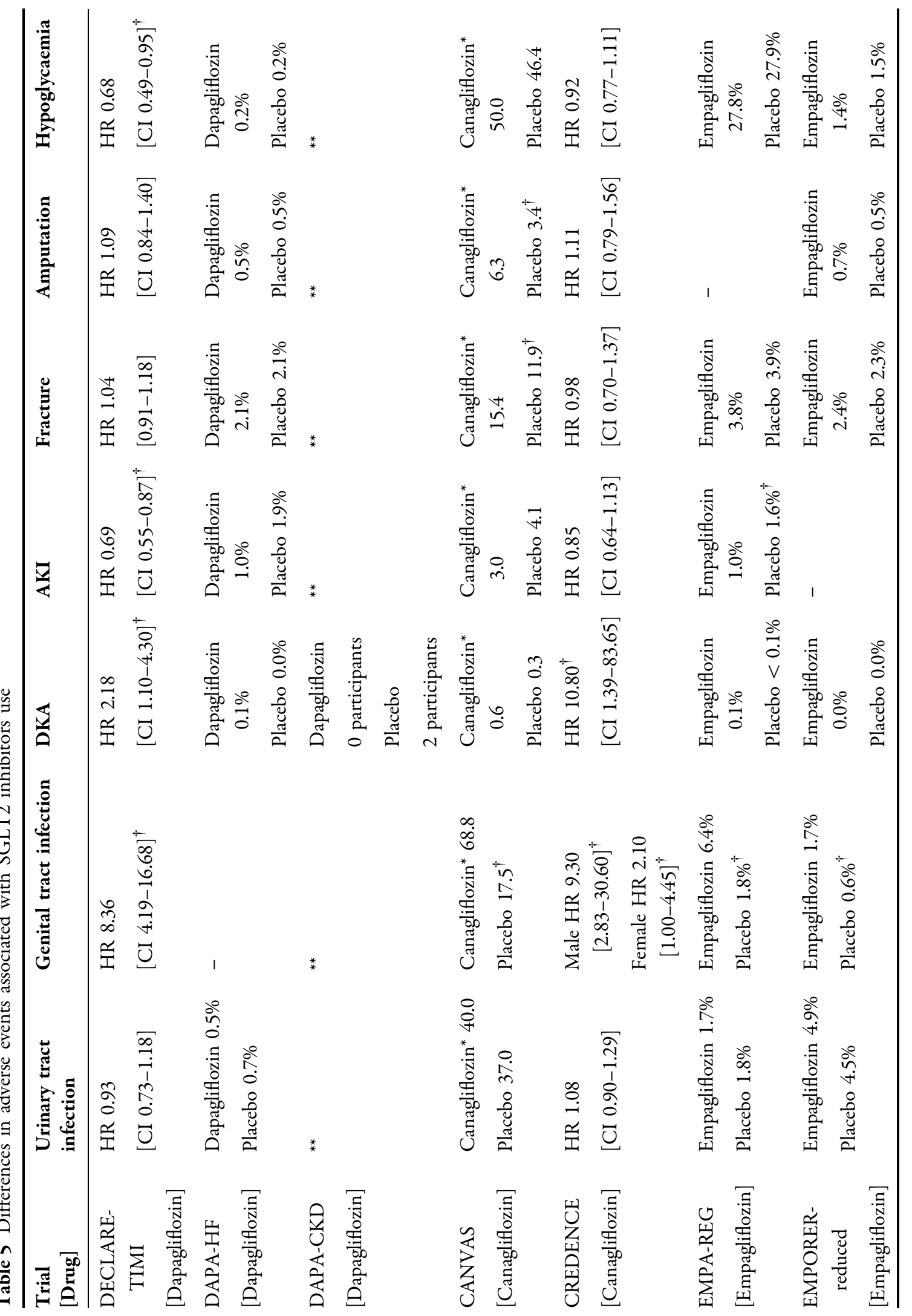




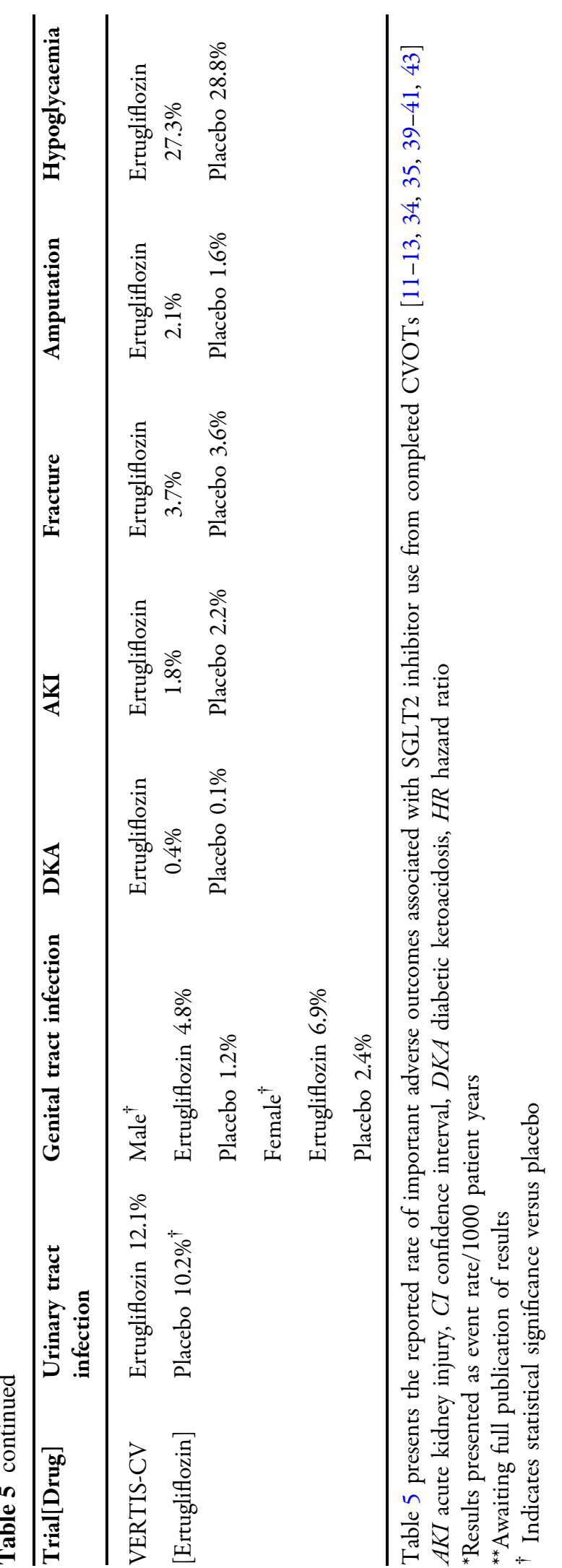

observed in bone [52]. Moreover, as the CREDENECE study also included canagliflozin and did not demonstrate an increased fracture risk, many believe this observation is simply a result of chance [53].

\section{CONCLUSIONS}

The use of SGLT2 inhibitors in clinical trials consistently results in improved cardiovascular risk factors, renal outcomes, HHF rates and does not lead to cardiovascular harm. However, there is some inconsistency with respect to 3-point MACE and cardiovascular mortality between different trials and even between trials investigating the same drug. These differences probably result from variations in the participant characteristics in each study and the subsequent cardiovascular event rate in each trial influencing statistical analysis. Yet, dissimilarities in their pharmacology such as their relative affinity for SGLT2 or pharmacodynamic properties may explain some of these differences. Nevertheless, there are now so many cardiovascular, renal and heart failure outcome trials with different study designs, interventions and outcomes it is increasingly difficult to see the wood from the trees. We await the full publication of the VERTIS-CV, DAPA-CKD, DELIVER and EMPEROR-preserved trials which we hope will shed some light on some of these discrepancies.

\section{ACKNOWLEDGEMENTS}

Funding. No funding or sponsorship was received for this study or publication of this article.

Authorship. All named authors meet the International Committee of Medical Journal Editors (ICMJE) criteria for authorship for this article, take responsibility for the integrity of the work, and have given their approval for this version to be published.

Disclosures. David M. Williams and Asif Nawaz have nothing to disclose. Marc Evans 
received financial support for consultancy from Novartis, Merck Sharp \& Dohme Corp. and Novo Nordisk and has served on the speaker's bureau for Novartis, Lilly, Boehringer lngelheim, Merck Sharp \& Dohme Corp., Novo Nordisk, Janssen and Takeda. Marc Evans is also the Editor-in-Chief of Diabetes Therapy.

Compliance with Ethics Guidelines. This article is based on previously conducted studies and does not contain any studies with human participants or animals performed by any of the authors.

Data Availability. Data sharing is not applicable to this article as no datasets were generated or analysed during the current study.

Open Access. This article is licensed under a Creative Commons Attribution-NonCommercial 4.0 International License, which permits any non-commercial use, sharing, adaptation, distribution and reproduction in any medium or format, as long as you give appropriate credit to the original author(s) and the source, provide a link to the Creative Commons licence, and indicate if changes were made. The images or other third party material in this article are included in the article's Creative Commons licence, unless indicated otherwise in a credit line to the material. If material is not included in the article's Creative Commons licence and your intended use is not permitted by statutory regulation or exceeds the permitted use, you will need to obtain permission directly from the copyright holder. To view a copy of this licence, visit http://creativecommons.org/licenses/bync/4.0/.

\section{REFERENCES}

1. Harding JL, Pavkov ME, Magliano DJ, et al. Global trends in diabetes complications: a review of current evidence. Diabetologia. 2019;62:3-16.

2. Trikkalinou A, Papazafiropoulou AK, Melidonis A. Type 2 diabetes and quality of life. World J Diabetes. 2017;8:120-9.
3. Hex N, Bartlett C, Wright D, Taylor M, Varley D. Estimating the current and future costs of type 1 and type 2 diabetes in the UK, including direct health costs and indirect societal and productivity costs. Diabet Med. 2012;29:855-62.

4. Nissen SE, Wolski K. Effect of rosiglitazone on the risk of myocardial infarction and death from cardiovascular causes. N Engl J Med. 2007;356: 2457-71.

5. Food and Drug Administration (FDA). Guidance for industry: diabetes mellitus-evaluating cardiovascular risk in new antidiabetic therapies to treat type 2 diabetes. 2008. www.fda.gov/downloads/ Drugs/

GuidanceComplianceRegulatoryInformation/ Guidances/ucm071627.pdf. Accessed 23 Sept 2020.

6. European Medicines Agency (EMA). Guideline on clinical investigation of medicinal products in the treatment or prevention of diabetes mellitus 2012 . https://www.ema.europa.eu/docs/en_GB/ document_library/Scientific_guideline/2012/06/ WC500129256.pdf. Accessed 23 Sept 2020.

7. Einarson TR, Acs A, Ludwig C, Panton UH. Prevalence of cardiovascular disease in type 2 diabetes: a systematic review of the scientific evidence from across the world in 2007-2017. Cardiovasc Diabetol. 2018;17:83.

8. Verma S, McMurray JJV. SGLT2 inhibitors and mechanisms of cardiovascular benefit: a state-ofthe-art review. Diabetologia. 2018;61:2108-17.

9. Zelniker TA, Wiviott SD, Raz I, et al. SGLT2 inhibitors for primary and secondary prevention of cardiovascular and renal outcomes in type 2 diabetes: a systematic review and meta-analysis of cardiovascular outcome trials. Lancet. 2019;393: 31-9.

10. Williams DM, Nawaz A, Evans M. Renal outcomes in type 2 diabetes: a review of cardiovascular and renal outcome trials. Diabetes Ther. 2020;11: 369-86.

11. American College of Cardiology. Evaluation of ertugliflozin efficacy and safety cardiovascular outcomes trial - VERTIS CV. 2020. https://www.acc. org/education-and-meetings/image-and-slidegallery/media-detail?id= 307A7E103BC04A588A3370709253FC35. Accessed 22 Sept 2020.

12. Zinman B, Wanner C, Lachin JM, et al. Empagliflozin, cardiovascular outcomes, and mortality in type 2 diabetes. N Eng J Med. 2015;373:2117-28. 
13. Neal B, Perkovic V, Mahaffey KW, et al. Canagliflozin and cardiovascular and renal events in type 2 diabetes. N Engl J Med. 2017;377(7):644-57.

14. Food and Drug Administration (FDA). Type 2 diabetes mellitus: evaluating the safety of new drugs for improving glycaemic control. Guidance for industry. 2020. https://www.fda.gov/regulatoryinformation/search-fda-guidance-documents/type2-diabetes-mellitus-evaluating-safety-new-drugsimproving-glycemic-control-guidance-industry. Accessed 22 Sept 2020.

15. List JF, Woo V, Morales E, Tang W, Fiedorek FT. Sodium-glucose cotransport inhibition with dapagliflozin in type 2 diabetes. Diabetes Care. 2009;32: 650-7.

16. Fitchett D, McKnight J, Lee J, et al. Empagliflozin (EMPA) reduces heart failure irrespective of control of blood pressure (BP), low density lipoprotein cholesterol (LDL-C) and HbA1c. Diabetes. 2017;66: A312-3.

17. Dekkers CCJ, Sjöström CD, Greasley PJ, Cain V, Boulton DW, Heerspink HJL. Effects of the sodiumglucose co-transporter-2 inhibitor dapagliflozin on estimated plasma volume in patients with type 2 diabetes. Diabetes Obes Metab. 2019;21:2667-73.

18. Matsutani D, Sakamoto M, Kayama Y, Takeda N, Horiuchi R, Utsunomiya K. Effect of canagliflozin on left ventricular diastolic function in patients with type 2 diabetes. Cardiovasc Diabetol. 2018;17: 73.

19. Tamargo J. Sodium-glucose cotransporter 2 inhibitors in heart failure: potential mechanisms of action, adverse effects and future developments. Eur Cardiol. 2019;14:23-32.

20. Heerspink HJ, Perkins BA, Fitchett DH, Husain M, Cherney DZ. Sodium glucose cotransporter 2 inhibitors in the treatment of diabetes mellitus: cardiovascular and kidney effects, potential mechanisms, and clinical applications. Circulation. 2016;134:752-72.

21. Crawford PA. Refueling the failing heart: a case for sodium-glucose cotransporter 2 inhibition in cardiac energy homeostasis. JACC Basic Transl Sci. 2018;3:588-90.

22. Packer M. SGLT2 inhibitors produce cardiorenal benefits by promoting adaptive cellular reprogramming to induce a state of fasting mimicry: a paradigm shift in understanding their mechanism of action. Diabetes Care. 2020;43:508-11.

23. Shigiyama F, Kumashiro N, Miyagi M, et al. Effectiveness of dapagliflozin on vascular endothelial function and glycemic control in patients with early-stage type 2 diabetes mellitus: DEFENCE study. Cardiovasc Diabetol. 2017;16:84.

24. Packer M, Anker SD, Butler J, Filippatos G, Zannad F. Effects of sodium-glucose cotransporter 2 inhibitors for the treatment of patients with heart failure: proposal of a novel mechanism of action. JAMA Cardiol. 2017;2:1025-9.

25. Lee TM, Chang NC, Lin SZ. Dapagliflozin, a selective SGLT2 inhibitor, attenuated cardiac fibrosis by regulating the macrophage polarization via STAT3 signaling in infarcted rat hearts. Free Radic Biol Med. 2017;104:298-310.

26. Dominguez Rieg JA, Rieg T. What does sodiumglucose co-transporter 1 inhibition add: prospects for dual inhibition. Diabetes Obes Metab. 2019;21: $43-52$.

27. Polidori D, Sha S, Mudaliar S, et al. Canagliflozin lowers postprandial glucose and insulin by delaying intestinal glucose absorption in addition to increasing urinary glucose excretion: results of a randomized, placebo-controlled study. Diabetes Care. 2013;36:2154-61.

28. US Food \& Drug Administration. 2013. Medication guide: Invokana (canagliflozin). https://www. accessdata.fda.gov/drugsatfda_docs/label/2020/ 204042s034lbl.pdf\#page $=48$. Accessed 23 Sept 2020.

29. US Food \& Drug Administration. 2014. Medication guide: Farxiga (dapagliflozin). https://www. accessdata.fda.gov/drugsatfda_docs/label/2020/ 202293s020lbl.pdf\#page $=47$. Accessed 23 Sept 2020.

30. US Food \& Drug Administration. 2014. Medication guide: Jardiance (empagliflozin). https://www. accessdata.fda.gov/drugsatfda_docs/label/2020/ 204629s023lbl.pdf\#page $=33$. Accessed 23 Sept 2020.

31. US Food \& Drug Administration. 2017. Medication guide: Steglatro (ertugliflozin). https://www. accessdata.fda.gov/drugsatfda_docs/label/2017/ 209803s000lbl.pdf. Accessed 23 Sept 2020.

32. Milder DA, Milder TY, Kam PCA. Sodium-glucose co-transporter type-2 inhibitors: pharmacology and peri-operative considerations. Anaesthesia. 2018;73:1008-18.

33. Kalra S, Shetty KK, Nagarajan VB, et al. Basic and clinical pharmaco-therapeutics of SGLT2 inhibitors: a contemporary update. Diabetes Ther. 2020;11: 813-33. 
34. Wiviott SD, Raz I, Bonaca MP, et al. Dapagliflozin and cardiovascular outcomes in type 2 diabetes. N Engl J Med. 2019;380:347-57.

35. McMurray JJV, Solomon SD, Inzucchi SE, et al. Dapagliflozin in patients with heart failure and reduced ejection fraction. N Engl J Med. 2019;381: 1995-2008.

36. Raz I, Wiviott SD, Yanuv I, et al. Effects of dapagliflozin on the urinary albumin-to-creatinine ratio in patients with type 2 diabetes: a predefined analysis from the DECLARE-TIMI 58 randomised, placebo-controlled trial. Diabetes. 2019;68:244-OR.

37. Mosenzon O, Wiviott SD, Cahn A, et al. Effects of dapagliflozin on development and progression of kidney disease in patients with type 2 diabetes: an analysis from the DECLARE-TIMI 58 randomised trial. Lancet Diabetes Endocrinol. 2019;7:606-17.

38. Wheeler DC, Stefansson BV, Batiushin M, et al. The dapagliflozin and prevention of adverse outcomes in chronic kidney disease (DAPA-CKD) trial: baseline characteristics. Nephrol Dial Transplant. 2020;35:1700-11.

39. European Society of Cardiology. 2020. DAPA-CKD trial meets primary endpoint in patients with chronic kidney disease. https://www.escardio.org/ The-ESC/Press-Office/Press-releases/DAPA. Accessed 23 Sept 2020.

40. Perkovic V, Jardine MJ, Neal B, et al. Canagliflozin and renal outcomes in type 2 diabetes and nephropathy. N Engl J Med. 2019;380:2295-306.

41. Perkovic V, de Zeeuw D, Mahaffey KW, et al. Canagliflozin and renal outcomes in type 2 diabetes: results from the CANVAS Program randomised clinical trials. Lancet Diabetes Endocrinol. 2018;6:691-704.

42. Wanner C, Inzucchi SE, Lachin JM, et al. Empagliflozin and progression of kidney disease in type 2 diabetes. N Eng J Med. 2016;375:323-34.

43. Packer M, Anker SD, Butler J, et al. Cardiovascular and renal outcomes with empagliflozin in heart failure. N Engl J Med. 2020. https://doi.org/10. 1056/NEJMoa2022190.

44. Cannon CP, McGuire DK, Pratley R, et al. Design and baseline characteristics of the eValuation of ERTugliflozin effIcacy and Safety CardioVascular outcomes trial (VERTIS-CV). Am Heart J. 2018;206: 11-23.

45. ClinicalTrials.gov. 2020. Dapagliflozin Evaluation to improve the LIVEs of patients with pReserved ejection fraction heart failure (DELIVER). https:// clinicaltrials.gov/ct2/show/NCT03619213. Accessed 23 Sept 2020.

46. Anker SD, Butler J, Filippatos GS, et al. Evaluation of the effects of sodium-glucose co-transporter 2 inhibition with empagliflozin on morbidity and mortality in patients with chronic heart failure and a preserved ejection fraction: rationale for and design of the EMPEROR-Preserved Trial. Eur J Heart Fail. 2019;21:1279-87.

47. Kluger AY, Tecson KM, Lee AY, et al. Class effects of SGLT2 inhibitors on cardiorenal outcomes. Cardiovasc Diabetol. 2019;18:99.

48. Liu J, Li L, Li S, et al. Sodium-glucose co-transporter2 inhibitors and the risk of diabetic ketoacidosis in patients with type 2 diabetes: a systematic review and meta-analysis of randomized controlled trials. Diabetes Obes Metab. 2020;22(9):1619-27.

49. Lega IC, Bronskill SE, Campitelli MA, et al. Sodium glucose cotransporter 2 inhibitors and risk of genital mycotic and urinary tract infection: a population-based study of older women and men with diabetes. Diabetes Obes Metab. 2019;21:2394-404.

50. Cahn A, Melzer-Cohen C, Pollack R, Chodick G, Shalev V. Acute renal outcomes with sodium-glucose co-transporter-2 inhibitors: real-world data analysis. Diabetes Obes Metab. 2019;21(2):340-8.

51. Haraguchi A, Shigeno R, Horie I, et al. The effect of luseogliflozin on bone microarchitecture in older patients with type 2 diabetes: study protocol for a randomized controlled pilot trial using secondgeneration, high-resolution, peripheral quantitative computed tomography (HR-pQCT). Trials. 2020;21:379.

52. Thrailkill KM, Nyman JS, Bunn RC, et al. The impact of SGLT2 inhibitors, compared with insulin, on diabetic bone disease in a mouse model of type 1 diabetes. Bone. 2017;94:141-51.

53. Zhou Z, Jardine M, Perkovic V, et al. Canagliflozin and fracture risk in individuals with type 2 diabetes: results from the CANVAS Program. Diabetologia. 2019;62:1854-67. 